\title{
Risk communication as a core public health competence in infectious disease management: Development of the ECDC training curriculum and programme
}

\author{
P Dickmann ${ }^{1}$, T Abraham $^{2}$, S Sarkar ${ }^{3}$, P Wysocki ${ }^{4}$, S Cecconi ${ }^{5}$, F Apfel ${ }^{5}$, Ü Nurm ${ }^{6}$ \\ 1. dickmann risk communication drc|, London, United Kingdom \\ 2. University of Hong Kong, Journalism and Media Studies, Hong Kong \\ 3. Independent Consultant, Geneva, Switzerland \\ 4. National AIDS Centre, Warsaw, Poland \\ 5. World Health Communication Associates (WHCA), Compton Bishop, United Kingdom \\ 6. European Centre for Disease Prevention and Control (ECDC), Stockholm, Sweden
}

Correspondence: Petra Dickmann (pdickmann@dickmann-drc.com)

Citation style for this article:

Dickmann P, Abraham T, Sarkar S, Wysocki P, Cecconi S, Apfel F, Nurm Ü. Risk communication as a core public health competence in infectious disease management: Development of the ECDC training curriculum and programme. Euro Surveill. 2016;21(14):pii=30188. D0I: http://dx.doi.org/10.2807/156o-7917. ES.2016.21.14.30188

Risk communication has been identified as a core competence for guiding public health responses to infectious disease threats. The International Health Regulations (2005) call for all countries to build capacity and a comprehensive understanding of health risks before a public health emergency to allow systematic and coherent communication, response and management. Research studies indicate that while outbreak and crisis communication concepts and tools have long been on the agenda of public health officials, there is still a need to clarify and integrate risk communication concepts into more standardised practices and improve risk communication and health, particularly among disadvantaged populations. To address these challenges, the European Centre for Disease Prevention and Control (ECDC) convened a group of risk communication experts to review and integrate existing approaches and emerging concepts in the development of a training curriculum. This curriculum articulates a new approach in risk communication moving beyond information conveyance to knowledge- and relationship-building. In a pilot training this approach was reflected both in the topics addressed and in the methods applied. This article introduces the new conceptual approach to risk communication capacity building that emerged from this process, presents the pilot training approach developed, and shares the results of the course evaluation.

\section{Background}

The International Health Regulations (IHR 2005) have been developed to help all countries better prepare and respond to public health emergencies of international concerns [1]. The importance of risk communication is recognised as one of the eight core capacities in the successful management of infectious diseases and other public health risks both in terms of gathering intelligence, and in enabling the functional flow of information, communication and coordination [2]. During a public health emergency time is short and important information, communication and coordination tasks such as identifying public communication focal points and stakeholders, developing and implementing reliable communication structures should be in place to allow systematic and coherent crisis communication and management [3].

Risk communication is understood in this context as serving a double role: risk communication should prepare for crisis management and it should build capacity for understanding and action competence as well as a comprehensive understanding of health risks among health officials and the general public. This capacity building is needed for peaks in demand and public health emergencies, as well as for managing continuous potential health threats, such as outbreaks of measles or the emergence of antimicrobial resistance.

Research studies indicate that while outbreak and crisis communication concepts and tools have long been on the agenda of public health officials, there is a need to better integrate conceptual approaches into sound practice in order to improve risk communication in health $[4,5]$.

Currently, there is little consensus about the meaning, impact and methods of risk communication in infectious disease contexts. Risk communication as a technical term emerged during the early 1970 s in the environmental health debates and has since then spread into different disciplines and discourses $[6,7]$. The understanding of risk communication as 'information 


\begin{tabular}{|c|c|c|c|c|}
\hline \multicolumn{2}{|c|}{ Risk communication activities } & \multirow{4}{*}{$\begin{array}{c}\text { Before } \\
\text { Public health emergency } \\
\text { Preparedness }\end{array}$} & \multirow{4}{*}{$\begin{array}{c}\text { During } \\
\text { Public health emergency } \\
\text { Response }\end{array}$} & \multirow{4}{*}{$\begin{array}{c}\text { After } \\
\text { Public health } \\
\text { emergency } \\
\text { Legacy }\end{array}$} \\
\hline \multirow{3}{*}{ Information } & Gathering & & & \\
\hline & Assessing & & & \\
\hline & Sharing & & & \\
\hline \multirow{3}{*}{ Communication } & Communications (actions: flyer, website, etc.) & & Crisis communications & \\
\hline & $\begin{array}{c}\text { Key messages / } \\
\text { Content }\end{array}$ & & & \\
\hline & $\begin{array}{l}\text { Strategy / } \\
\text { Methods }\end{array}$ & & & \\
\hline \multirow{4}{*}{ Coordination } & Local & & & \\
\hline & Regional & & & \\
\hline & National & & & \\
\hline & International & & & \\
\hline
\end{tabular}

exchange about health risks caused by environment, industrial, or agricultural, processes, policies, or products among individuals, groups and institutions' [7] has become more prominent post 11 September 2001. The conceptual foundations of risk communication draw on complex social, cognitive and psychological research in a wide variety of areas including behavioural communications, environmental health, health promotion, governance and social marketing [7]. The public health practice of risk communication, however, has been slow to embrace such a broader perspective and mainly focussed on approaches to improve risk communication as the communication of risks from public health authorities to their public $[8,9]$.

Efforts to broaden this approach face three substantial challenges:

It is not known how it is to be done. While there are a plethora of practical guidelines, best-practice examples and ad hoc advice (e.g. WHO outbreaks communications [10], United States Centers for Disease Control Crisis Emergency and Risk Communication [11]), this advice is mainly orientated towards communicating risks in outbreak and crisis situations [12]. While there is a multitude of conceptual approaches to risk perception and communication, e.g. Slovic $[13,14]$, Fischhoff/ Morgan [15,16] and Kasperson [17], there is little integration of these approaches into risk communication in public health practice.

There is a lack of skilled individuals and formal training and practical experience is scarce as the approach has not entered into mainstream public health academia and learning [18].

Finally, there is a lack of supportive environments. Even though risk communication has been designated as a core IHR capacity, it has yet to be routinely implemented into public health organisation planning, its risk assessment, and management procedures [19].

Acknowledging these points, the European Centre for Disease Prevention and Control (ECDC) initiated the development of a training curriculum and programme to address the need for both conceptual and practical capacity building in risk communication as an integral component of disease prevention and control. Practitioners and researchers on the forefront of risk communication practise were invited to develop a new conceptual approach to capacity building and develop a teaching curriculum. The initial focus of the training was on vaccine preventable diseases, in particular enhancing measles vaccination uptake, and was first tested with ECDC and European Commission experts in January 2013.

\section{Concept review, integration and development}

\section{Working definitions}

Risk and crisis communication differ in many aspects and there is terminological and epistemological ambiguity in international fora and discussions regarding definitions and approaches [20]. As a working definition we used time, method and content to distinguish between risk communication and crisis communication. Risk communication starts before crisis and continues throughout and after a crisis, is less directive compared with crisis communication, and has more time to explain even difficult and contradicting scientific positions. It also has the time and opportunity to offer diverse approaches to bridge the gap between the scientific assessment of health risks and public perceptions of health risks. The main activity areas of risk communication are information gathering, sharing 
and assessing, communication strategy, key messages and communications and coordination on different geographical and organisations levels (Table 1). Crisis communication is the communication during an outbreak when people need to know exactly what to do if they are affected and how to protect themselves and others. Effective communications is vital to prevent surges of low risk patients blocking medical infrastructures and to prevent the further transmission of the disease by enabling people to adopt e.g. the right behaviours. During an outbreak, time is short and crisis communication therefore needs to be concise and often unidirectional. Table 1 displays the main activity areas of risk communication and can be used to structure the strategic thinking around risk communication needs and gaps. It also helps clarify the distinction between working definitions of risk communication and crisis communications.

\section{Conceptual approach communication models}

Risk communication goes beyond communications of risks. It entails building public health capacity to enable, encourage and empower different publics to understand and act on health risks $[21,22]$ Yet, public health officials often see their tasks as predominantly providing information. They tend to rely mainly on an early information technology paradigm that assumes a rather static and unilateral sender who conveys messages to addressable recipients [23]. The reality of communication and information has been transformed. The public is no longer seen as a passive entity to be given recommendations and guidelines to follow by institutions which are to be trusted. The sender-message-recipient communication model does not cater for understanding how humans process information, communicate and make behavioural decisions. The popularity and increasingly important intelligence gathering and information dissemination functions of interactive social media (e.g. Facebook, Twitter, LinkedIn, etc.) is a strong indicator of the growing influence of decentralised and user-generated connectivity and is rapidly changing communication marketplaces [24].

\section{A new approach for risk communication in public health \\ The proposed risk communication concept for public health builds on theories and models from a variety of disciplines and applies a reflective approach. It calls for strategic shifts in thinking and approach to risk communication namely:}

1. From telling to listening: Risk communication is viewed as a complex process. It is as concerned with listening and understanding as it is with providing information and advice. Having listened and understood peoples' different perceptions and behaviours allows for quicker and more effective communication when time is short. Much can be learned in this area from behavioural communications models; which, for example, emphasise listening and gathering insights about what really motivates and moves the people to whom you are trying to communicate [25].

2. From information transfer to relationship building: Risk communication is not seen as exclusively based on information transmission, but as a strategic activity concerned with relationship building between authorities and the public over time [26]. Engaging affected populations early in development, planning, ongoing monitoring and evaluation enhances peoples' sense of empowerment and ownership. Much can be learned in this area from social marketing approaches; which, for example, emphasise the importance of 'exchange theory'- to understand the benefits and rewards for a given behaviour $[27,28]$.

3. From 'command and control' to creating supportive environments: Risk communication is not just about directive action, but is concerned with creating supportive environments where people can make their own informed decisions. Much can be learned in this area from health promotion approaches; which, for example emphasises the importance of 'environmental' factors on behaviour and the need 'to make the healthy choice the easy choice.' [29]

4. From siloed to coordinated approaches: Multiple actors and sectors are inevitably involved with all risk communication related issues. Risk communication is concerned with integration and partnership. Much can be learned in this area from new governance approaches which, for example, emphasise 'wholeof-government' and 'whole-of-society' approaches $[30,31]$.

\section{Conceptual approach to training curriculum:} methods and contents

This conceptual re-framing was reflected both in the topics addressed and in the methods applied.

The new risk communication training views risk and crisis communication as related but distinct realities. Although risk communication is seen as the foundation on which successful crisis communication can refer and rely on, risk communication is seen as having a different broader social format, rationale and rules. Risk communication has more to do with knowledgeand relationship building than simple information conveyance.

The training adopted a deconstructive approach and facilitated a look at the discourses that shape people's decisions and behaviour.

The training aimed to help participants to understand the concepts that underlie risk communication advice before they are able to really implement 'good advice' on risk communication strategies into their own realities. The new risk communication adopts a reflective approach. Rather than emphasising detailed guidance that lists the steps to go from $A$ to $B$, the training aimed 
to provide participants with a map, the skill and literacy to read the map and the ability to design their own risk communication strategies that work in their realities. Finally, an interactive, critical and reflective process in groups is emphasised. Rather than listening to lectures, a hands-on approach was used that engaged with participants and facilitated active learning, understanding and networking.

\section{Objectives, organisational and methodological approach}

The pilot training addressed public health and communication experts working at ECDC and the Commission of the European Union. The overall objective was to develop the competencies of public health programme managers and practitioners to analyse, understand and apply risk communication concepts, principles and approaches to the prevention and control of communicable disease threats on regional, national and/or local levels.

Each day of the two-day course was organised into reflection and action sessions. The days started with reflection sessions introducing terms, definitions, approaches, and gave time to discuss these. The afternoons were dedicated to actions: exploring ways to put concepts into practice, testing ideas, working on scenarios related to both on-going and crisis challenges, discussing and getting feedback from others within small working groups and in the plenum.

In order to maximise the utility of the discussions and ensure 'real-life' learning, each participant was asked to complete a pre-course assignment that included the development of a case study based on their own contextually specific experience. These case studies informed group work and plenum discussions.

The training was evaluated with a pre- and post-course questionnaire as well as day assessments at the end of first and the second day.

\section{Pre-course assessment}

Seven of 14 respondents considered themselves as having good knowledge of risk communication theories and 7 of 15 respondents had 'significant' or better experience in applying risk communication. The reason to participate in the training was mainly to receive a more formal training in risk communication as this was considered important for their field of work.

Expectations were practical and conceptual: participants wished for a structured approach, practical examples and tools; they also hoped for a better understanding of the different concepts and approaches.

Asked for a working understanding of risk communication, participants saw communication and risk communication as instruments to ensure trust and transparency; they stressed the importance of risk communication in the prevention of infectious diseases and as foundation for crisis communication. The nature of risk communication was seen in the communication of risks and to provide information adapted to various people; risk communication in this meaning was seen as ability to respond to public information needs. Ultimately risk communication should empower people as better-informed people are more likely to modify their behaviour.

\section{Post-course assessment}

After the course, 14 of 15 respondents reported that their expectations had been fully met and 14 of 16 stated that their understanding of concepts and approaches had increased considerably.

Participants, who said earlier that they had good knowledge and understanding of risk communication, expressed the need for a paradigmatic change in the understanding and institutional practice of risk communication and felt better prepared to advocate for this change. The majority felt that the training was very useful and they provided constructive feedback to individual sections in the day assessments. Overall, they appreciated that the training was based on a reflective and reframing approach rather than on providing tips, checklists and concrete guidance.

\section{Conclusion}

The training pilot was successful in conceptualising, articulating and introducing a new approach towards training the trainers in risk communication in public health. Further systematic analysis and evaluations of risk communication approaches and trainings are necessary to develop the capacity on the ground that is needed for the prevention of and response to public health incidents and emergencies. Future training in national and local settings will improve the curriculum and practice of risk communication and provide insights into the situation and landscape of risk communication on the ground and enhance our understanding of the practice of risk communication.

The ECDC as developer and advocate of this training and approach is in a unique position to be an efficient broker of knowledge and experience between the many centres of expertise around and beyond Europe and those in the EU countries responsible for risk communication policy and practice in public health.

\section{Acknowledgements}

The training was founded by Specific contract N. Twelve ECDC3442 Implementing Framework Contract N: ECDC/09/030 between World Health Communication Associates (WHCA) and ECDC.

Authors' contributions

All authors have been involved in concept development and training design. PD wrote the draft and did the evaluation; all authors have commented on the draft and approve the final version. 


\section{Conflicts of Interest}

The authors declare that they do not have a conflict of interest.

\section{References}

1. World Health Organization (WHO) Fifty-Eight World Health Assembly. Resolution WHA58.3. Revision of the International Health Regulations. Geneva: WHO;2005. Available from: http:// www.who.int/csr/ihr/WHA58-en.pdf

2. Apfel F. Health Communication. In: Cragg L, editor. Health Promotion Theory 2nd edition, Open University Press 2013. p. 141-57.

3. Dickmann P, Rubin GJ, Gaber W, Wessely S, Wicker S, Serve H, et al. New influenza A/ $\mathrm{H}_{1} \mathrm{~N}_{1}$ ("swine flu"): information needs of airport passengers and staff. Influenza Other Respi Viruses. 2011;5(1):39-46. DOI: 10.1111/j.1750-2659.2010.00168.x PMID: 21138539

4. European Centre for Disease Prevention and Control (ECDC). A literature review on effective risk communication for the prevention and control of communicable diseases in Europe. Stockholm: ECDC, 2013. Available from: http://ecdc.europa. eu/en/publications/Publications/risk-communication-literaryreview-jan-2013.pdf

5. Larson HJ, Jarrett C, Eckersberger E, Smith DM, Paterson $P$. Understanding vaccine hesitancy around vaccines and vaccination from a global perspective: a systematic review of published literature, 2007-2012.Vaccine. 2014;32(19):2150-9. DOI: 10.1016/j.vaccine.2014.01.081 PMID: 24598724

6. Fischhoff B. Risk perception and communication unplugged: twenty years of process. Risk Anal. 1995;15(2):137-45. DOI: 10.1111/j.1539-6924.1995.tb00308.x PMID: 7597253

7. Glik DC. Risk communication for public health emergencies. Annu Rev Public Health. 2007;28(1):33-54. DOI: 10.1146/ annurev.publhealth.28.021406.144123 PMID: 17222081

8. Covello V, McCallum D, Pavlova M. Effective risk communication: the role and responsibility of government and nongovernment organizations New York, NY: Plenum; 1989.

9. Sandman PM. Risk communication: facing public outrage.EPA J. 1987;13(21):21-2.Available from: http://www.psandman.com/ articles/facing.htm

10. World Health Organization (WHO). WHO Outbreak communication guidelines. Geneva: WHO; 2005. Available from: http://www.who.int/csr/resources/publications/WHO CDS_2005_28en.pdf

11. Centers for Disease Control and Prevention (CDC). Crisis Emergency and Risk Communication 2012 Edition. Available from: http://emergency.cdc.gov/cerc/resources/pdf/ cerc_2012edition.pdf

12. Abraham T. Lessons from the pandemic: the need for new tools for risk and outbreak communication.Emerg Health Threats J. 2011;4(0):7160. DOI: 10.3402/ehtj.v4io.7160 PMID: 24149033

13. Burns WJ, Slovic P. Risk perception and behaviors: anticipating and responding to crises. Risk Anal. 2012;32(4):579-82. DOI: 10.1111/j.1539-6924.2012.01791.x PMID: 22500649

14. Slovic P. Perception of risk.Science. 1987;236(4799):280-5. DOI: $10.1126 /$ science.3563507 PMID: 3563507

15. Atman CJ, Bostrom A, Fischhoff B, Morgan MG. Designing risk communications: completing and correcting mental models of hazardous processes, Part I.Risk Anal. 1994;14(5):779-88. DOI: 10.1111/j.1539-6924.1994.tbo0289.x PMID: 7800862

16. Bostrom A, Atman CJ, Fischhoff B, Morgan MG. Evaluating risk communications: completing and correcting mental models of hazardous processes, Part II.Risk Anal. 1994;14(5):789-98. DOI: 10.1111/j.1539-6924.1994.tbo0290.x PMID: 7800863

17. Kasperson J, Kasperson R, Pidgeon N, Slovic P. The social amplification of risk: assessing fifteen years of research and theory. In: Pidgeon N, Kasperson R, Slovic P, editors. The Social Amplification of Risk. Cambridge: Cambridge University Press; 2003. p. 13-46.

18. European Centre for Disease Prevention and Control (ECDC). Health communication and its role in the prevention and control of communicable diseases in Europe - Current evidence, practice and future developments. Stockholm: ECDC; 2014. Available from: http://ecdc.europa.eu/en/publications/ Publications/health-communication-communicable-diseaseeurope.pdf

19. European Centre for Disease Prevention and Control (ECDC). Public health stakeholders' perceived status of health communication activities for the prevention and control of communicable diseases across the EU and EEA/EFTA countries. Stockholm: ECDC; 2012. Available from: http://
ecdc.europa.eu/en/publications/Publications/20120620_TER_ StatusHealthComm.pdf

20. Abraham T. Risk and outbreak communication: lessons from alternative paradigms. Bull World Health Organ. 2009;87(8):604-7. DOI: 10.2471/BLT.08.058149 PMID: 19705010

21. Larson HJ. Negotiating vaccine acceptance in an era of reluctance.Hum Vaccin Immunother. 2013;9(8):1779-81. DOI: 10.4161/hv.25932 PMID: 23896582

22. European Centre for Disease Prevention and Control (ECDC). Literature review on trust and reputation management in communicable disease in public health. Stockholm: ECDC; 2011.

23. Weaver WS. Shannon CE. The Mathematical Theory of Communication. Urbana: University of Illinois Press; 1963.

24. Neiger BL, Thackeray R, Burton SH, Giraud-Carrier CG, Fagen MC. Evaluating social media's capacity to develop engaged audiences in health promotion settings: use of Twitter metrics as a case study. Health Promot Pract. 2013;14(2):157-62. DOI: 10.1177/1524839912469378 PMID: 23271716

25. UNICEF. Behaviour change communication in emergencies: $A$ toolkit. Nepal: UNICEF ROSA; 2006.Available from: http://www. unicef.org/rosa/Behaviour.pdf

26. European Centre for Disease Prevention and Control (ECDC). Evidence review: social marketing for the prevention and control of communicable disease. Stockholm: ECDC; 2012. Available from: http://ecdc.europa.eu/en/publications/ Publications/Social-marketing-prevention-control-ofcommunicable-disease.pdf

27. French J, Blair-Stevens C, Merrit R, McVey D. Social marketing and public health, theory and practice. Oxford: Oxford University Press; 2009.

28. European Centre for Disease Prevention and Control (ECDC). Social marketing guide for public health managers and practitioners. Stockholm ECDC, 2014. Available from: http:// ecdc.europa.eu/en/publications/Publications/socialmarketing-guide-public-health.pdf

29. World Health Organization (WHO). The Ottawa Charter for Health Promotion. Ottawa, Canada 1986. Available from: http://www.who.int/healthpromotion/conferences/previous/ ottawa/en/

30. WHO Regional Office for Europe (WHO). Implementing a Health 2020 Vision: Governance for Health in the 21st CenturyMaking it Happen. Copenhagen: WHO; 2013.

31. WHO Regional Office for Europe (WHO). Governance for health in the 21st century. Copenhagen, WHO; 2013.

\section{License and copyright}

This is an open-access article distributed under the terms of the Creative Commons Attribution (CC BY 4.0) Licence. You may share and adapt the material, but must give appropriate credit to the source, provide a link to the licence, and indicate if changes were made.

This article is copyright of the authors, 2016. 